\title{
ANALISIS PENGARUH PENGGUNAAN DROP PANEL TERHADAP NILAI MOMEN LENTUR DAN GESER PONS FLAT SLAB DENGAN METODE ELEMEN HINGGGA
}

\author{
Tohar Wijaya ${ }^{1}$ dan Leo S. Tedianto ${ }^{2}$ \\ ${ }^{1}$ Program Studi Sarjana Teknik Sipil, Universitas Tarumanagara, Jl. Letjen S. Parman No.1 Jakarta \\ Email: toharwijaya@gmail.com \\ ${ }^{2}$ Program Studi Sarjana Teknik Sipil, Universitas Tarumanagara, Jl. Letjen S. Parman No.1 Jakarta \\ Email:leotedi@gmail.com
}

\begin{abstract}
ABSTRAK
Beberapa saat kebelakang ini, pertumbuhan pembangunan infrastruktur dan gedung sangatlah tinggi. Berbagai inovasi dan pembaharuan pun muncul dalam bidang konstruksi, salah satunya pelat lantai. Flat slab adalah salah satu contohnya. Flat slab sendiri adalah konstruksi struktur pelat beton bertulang yang tidak menggunakan elemen balok, dimana pelat langsung ditopang oleh kolom dimana dalam beberapa kondisi digunakan drop panel untuk menahan gaya yang timbul pada daerah sekitar kolom. Gaya yang timbul pada daerah kolom itu adalah gaya geser dua arah atau biasa disebut gaya geser pons (punching shear). Pada pembahasan kali ini, dilakukan analisis mencari besarnya nilai momen lentur dan gaya geser pons pada flat slab dengan menggunakan bantuan aplikasi Finite Element Analysis (FEA). Nilai momen lentur dan gaya geser dibandingkan antara flat slab tanpa penggunaan drop panel dan flat slab dengan penggunaan drop panel. Tujuan dari pembahasan kali ini adalah untuk mengetahui pengaruh penggunaan drop panel pada konstruksi flat slab terhadap nilai momen lentur dan geser pons yang terjadi. Metode yang digunakan adalah finite element method serta metode analisis teoritis berdasarkan SNI. Kesimpulan yang didapat, adalah penggunaan drop panel pada flat slab menurunkan gaya geser pons dan momen lentur di daerah lapangan pada struktur flat slab.
\end{abstract}

Kata kunci: flat slab, drop panel, finite element analysis, momen lentur, geser pons 


\section{PENDAHULUAN}

Berbagai macam jenis konstruksi berkembang seiring dengan perkembangan zaman, termasuk dalam konstruksi pelat lantai (slab). Pada mulanya hanya dikenal konstruksi pelat konvensional (conventional slab). Pelat konvensional umumnya tersusun atas komponen plat lantai, balok anak, balok induk dan kolom. Sedangkan menurut SNI 2847:2013 ada plat jenis lain selain plat konvensional, yaitu plat yang langsung didukung oleh kolom dengan atau tanpa penebalan plat di atas kolom (drop panel) yang kemudian dikenal dengan plat cendawan (flat slab).

Beberapa saat kebelakang, konstruksi pelat cendawan atau biasa disebut dengan istilah flat slab mulai banyak digunakan karena beberapa keuntungan. Keuntungan flat slab menurut (Asroni , 2010) yaitu fleksibilitasnya terhadap tata ruang; waktu pengerjaannya relatif lebih pendek, hal ini dapat dilihat dari proses pembuatan bekisting pelat yang langsung dapat dibuat merata secara keseluruhan tanpa harus membuat bekisting balok baloknya terlebih dahulu; kemudahan dalam pemasangan instalasi mekanikal dan elektrikal; menghemat tinggi bangunan (tinggi ruang bebas lebih besar dikarenakan tidak adanya pengurangan ketinggian akibat balok dan komponen pendukung struktur lainnya); pemakaian tulangan pelat bisa dengan tulangan fabrikasi (welded wire mesh).

Namun kelebihan flat slab diiringi pula dengan beberapa kelemahan. Salah satu kelemahan yang paling utama adalah punching shear (geser pons) yang timbul pada daerah kolom. Salah satu cara untuk mengatasi punching shear (geser pons) yang timbul adalah dengan penggunaan drop panel. Drop panel sendiri adalah penebalan pada daerah kepala kolom. Pada pembahasan kali ini, akan dibahas mengenai pengaruh penggunaan drop panel terhadap nilai momen lentur dan geser pada konstruksi flat slab. Akan diambil sampel flat slab tanpa penggunaan drop panel dibandingkan dengan flat slab dengan penggunaan drop panel. Pembahasan akan difokuskan pada nilai momen lentur dan gaya geser yang timbul.

\section{METODE ELEMEN HINGGA}

Pada penelitian kali ini, analisis dilakukan dengan dua cara yaitu analisis metode elemen hingga dan analisis teoritis berdasarkan SNI.

\section{Pengertian}

Metode Elemen Hingga atau Finite Element Method (FEM) adalah metode numeris untuk penyelesaian masalah teknik dan fisika matematis.

Metode Elemen Hingga adalah metode yang dapat menyelesaikan persamaan yang dianalisa dalam sistem persamaan secara serentak dengan cara memberikan nilai pendekatan dari nilai sebenarnya pada titik tertentu dalam sistem yang continue.

Cara kerja metode elemen hingga adalah dengan memecah (mendiskritisasi) atau dalam bahasa inggris disebut meshing merupakan suatu proses pemodelan sebuah struktur atau objek dengan membaginya ke dalam elemenelemen kecil (elemen hingga) yang terhubung oleh dua atau lebih titik (nodes) dan digunakan sebagai batas dari struktur atau objek tersebut. Dalam metode elemen hingga, tidak dilakukan pemecahan permasalahan elemen struktur secara keseluruhan dalam satu kali operasi, melainkan membuat formulasi persamaan untuk masing-masing elemen hingga, kemudian menggabungkannya untuk memperoleh solusi untuk elemen strukturnya. Secara singkat, solusi dari permasalahan struktur yang dimaksud adalah menghitung besarnya perpindahan dan tegangan yang dialami struktur akibat adanya beban yang bekerja (Logan, 2011).

\section{Kondisi batas}

Pada analisa suatu struktur, kita harus menspesifikasikan kondisi batas yang ada sesuai dengan masalah yang akan dianalisa. Dengan dimasukkan kondisi batas tersebut, maka matriks kekakuan suatu struktur dapat direduksi, sehingga dapat menyederhanakan perhitungan.

$>$ Untuk gerakan translasi-rotasi, tanda coret berarti bahwa gerakan pada arah derajat kebebasan tersebut dikekang atau ditahan.

$>$ Untuk aksi gaya-momen, tanda coret berarti bahwa tidak ada gaya atau momen pada arah derajat kebebasan itu.

$>$ Perlu diingat bahwa pada tabel diatas, gambar rotasi ataupun momen hanya dipakai untuk menunjukkan apakah derajat kebebasan yang bersangkutan dikekang atau tidak. Jadi arah rotasi ataupun momen (apakah searah atau berlawanan jarum jam) tidak berpengaruh. 


\section{Program finite element analysis}

Pada pembahasan kali ini, desain yang digunakan adalah sebagai berikut:

1) Analisis numerik, Metode Elemen Hingga menggunakan program berbasis Finite Element Analysis (FEA).

2) Peraturan yang dipakai sebagai acuan adalah SNI 2847-2013.

3) Studi difokuskan pada perbandingan antara momen lentur serta gaya geser pons dengan kondisi ada drop panel dan dengan kondisi tidak ada drop panel.

4) Tulangan tidak dimodelkan dalam struktur (analisis hanya beton saja).

5) Panel pelat lantai yang digunakan berukuran $24 \mathrm{~m} \times 24 \mathrm{~m}$, dengan jarak antar kolom adalah simetris $6 \mathrm{~m} \times$ $6 \mathrm{~m}$.

6) Dimensi kolom, ketebalan drop panel, serta ketebalan flat slab diambil berdasarkan SNI 2847-2013

7) Ketebalan flat slab diambil $150 \mathrm{~mm}$

8) Drop panel diambil berbentuk persegi dengan ukuran 2000mm x 2000mm dengan ketebalan bervariasi yaitu $50 \mathrm{~mm}, 75 \mathrm{~mm}, 100 \mathrm{~mm}, 125 \mathrm{~mm}$, dan $150 \mathrm{~mm}$.

9) Ukuran kolom digunakan 500mm x 500mm

10) Perletakan kolom digunakan jepit

11) Untuk pelat lantai dan drop panel digunakan f'c $30 \mathrm{Mpa}$

12) Untuk kolom digunakan f'c $40 \mathrm{Mpa}$

13) Tinggi kolom digunakan 3 meter

14) Beban Dead Load $=1 \mathrm{kN} / \mathrm{m} 2$, Beban Live Load $=4 \mathrm{kN} / \mathrm{m} 2$

15) Kombinasi pembebanan Service ( $D L=1$ dan $L L=1)$ dan Ultimate ( $D L=1,2$ dan $L L=1,6)$

16) Poisson's Ratio 0,2

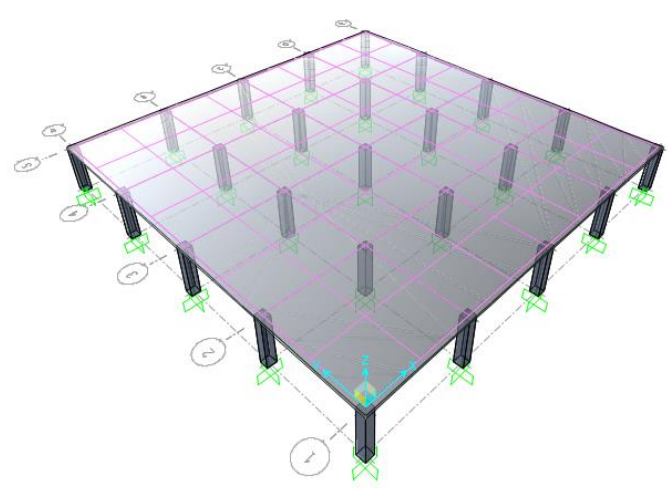

Gambar 1. Flat Slab tanpa Drop Panel

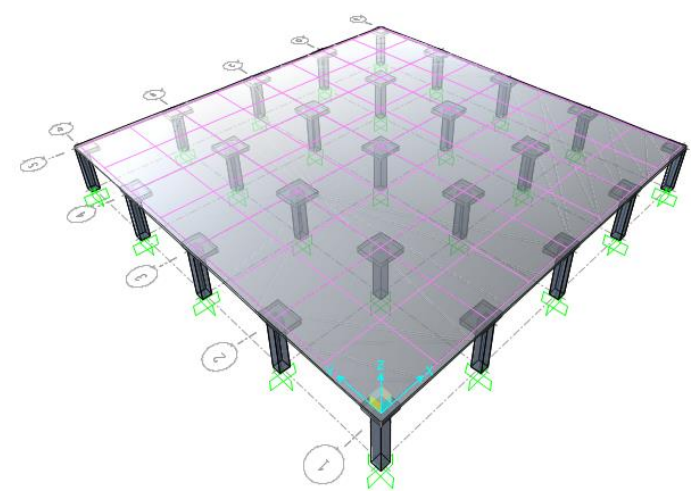

Gambar 2. Flat Slab dengan Drop Panel

\section{Momen lentur}

Momen Lentur Total $\left(M_{o}\right)$ dapat diperoleh dari persamaan:

$$
\text { Mo }=\frac{q_{u} l_{2} l_{n}^{2}}{8}
$$

dengan $q_{u}=$ gaya merata terfaktor, $l_{2}=$ jarak antar kolom arah tegak lurus, $I_{n}=$ jarak bersih dalam arah sejajar 
Analisis Pengaruh Penggunaan Drop Panel terhadap Nilai

Tohar Wijaya, et al. Momen Lentur dan Geser Pons pada Flat Slab 


\section{ANALISIS DAN PEMBAHASAN}

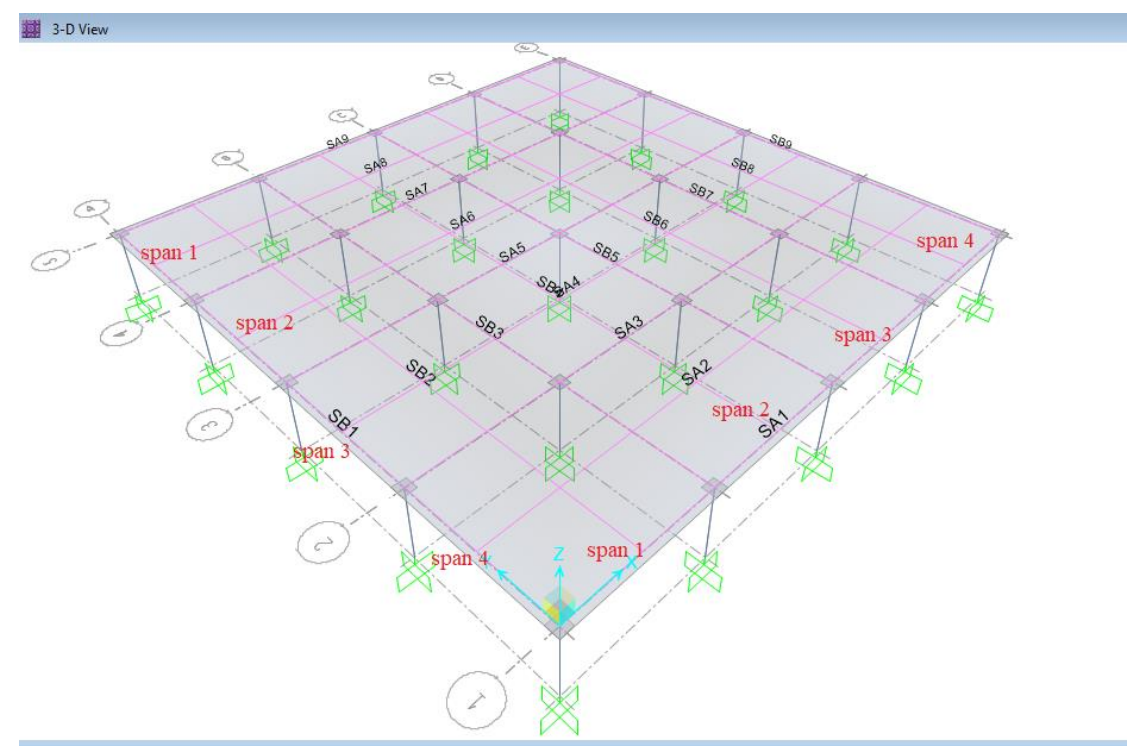

Gambar 3. Penamaan Pelat Lantai

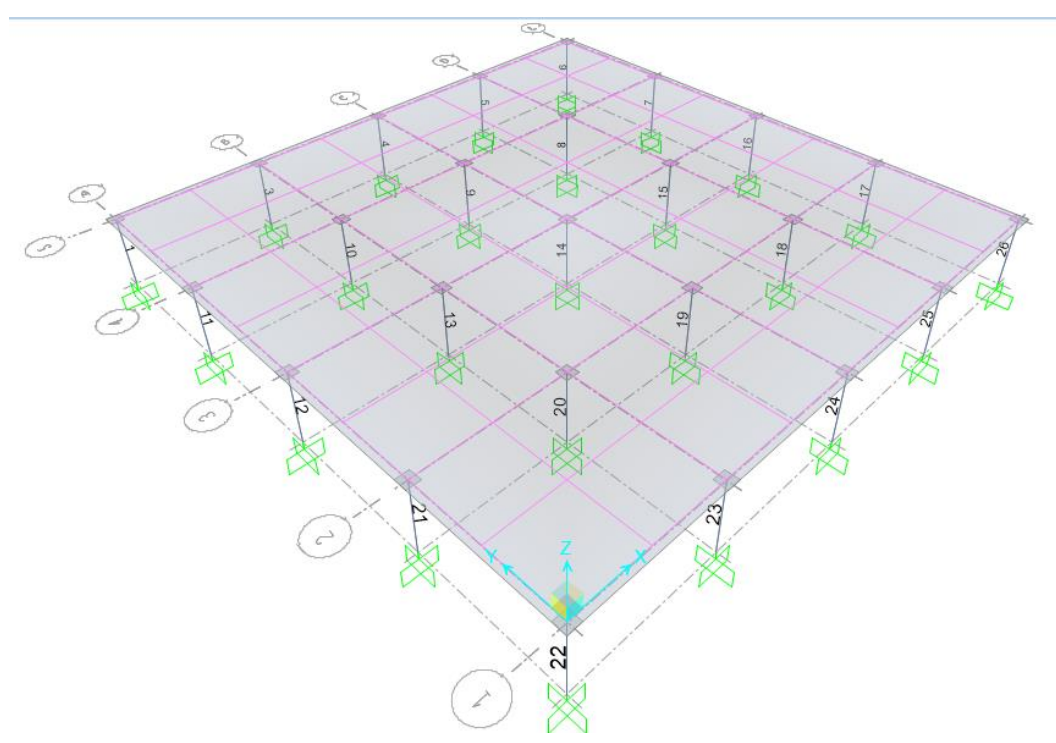

Gambar 4. Penamaan Titik Geser Pons

Analisis momen lentur akan dilakukan pada SA1, SA2, SA3, SA4, dan SA5 serta pada Span 1 dan Span 2. Untuk penamaan titik geser pons adalah sebagai berikut.

Titik 1,6,22,26 = Titik A

Titik 3,5,7,17,25,23,11,21 = Titik B

Titik 12,4,16,24= Titik C

Titik 8,10,18,20 = Titik D

Titik 13,9,15,19 = Titik E

Titik $14=$ Titik F 
Tabel 1. Momen Lentur Flat Slab

\begin{tabular}{|c|c|c|c|c|c|c|c|c|}
\hline \multirow[b]{2}{*}{ Strip } & \multirow[b]{2}{*}{ Span } & \multirow[b]{2}{*}{ Location } & \multicolumn{2}{|c|}{ Tanpa Drop Panel } & \multicolumn{2}{|c|}{ Drop Panel $50 \mathrm{~mm}$} & \multicolumn{2}{|c|}{ Drop Panel $100 \mathrm{~mm}$} \\
\hline & & & $\begin{array}{c}\text { Top } \\
\text { Moment } \\
(k N m)\end{array}$ & $\begin{array}{l}\text { Bottom } \\
\text { Moment } \\
(\mathrm{kNm})\end{array}$ & $\begin{array}{c}\text { Top } \\
\text { Moment } \\
(k N m)\end{array}$ & $\begin{array}{c}\text { Bottom } \\
\text { Moment } \\
(\mathrm{kNm})\end{array}$ & $\begin{array}{c}\text { Top } \\
\text { Moment } \\
(\mathrm{kNm}) \\
\end{array}$ & $\begin{array}{c}\text { Bottom } \\
\text { Moment } \\
(\mathrm{kNm})\end{array}$ \\
\hline SA1 & Span 1 & Start & $-74,9109$ & - & $-92,5485$ & - & $-104,5618$ & - \\
\hline SA1 & Span 1 & Middle & - & 38,4349 & - & 32,047 & - & 28,5852 \\
\hline SA1 & Span 1 & End & $-84,3229$ & - & $-99,3893$ & - & $-111,2606$ & - \\
\hline SA1 & Span 2 & Start & $-78,7791$ & - & $-91,6609$ & - & $-100,6433$ & - \\
\hline SA1 & Span 2 & Middle & - & 33,2815 & - & 27,3134 & - & 23,9237 \\
\hline SA1 & Span 2 & End & $-77,3711$ & - & $-90,2215$ & - & $-99,169$ & - \\
\hline $\mathrm{SA} 2$ & Span 1 & Start & 0 & - & 0 & - & 0 & - \\
\hline SA2 & Span 1 & Middle & - & 56,9966 & - & 49,0127 & - & 44,5599 \\
\hline $\mathrm{SA} 2$ & Span 1 & End & $-36,7043$ & - & $-31,2174$ & - & $-1,8494$ & - \\
\hline $\mathrm{SA} 2$ & Span 2 & Start & $-36,7043$ & - & $-31,2174$ & - & $-26,156$ & - \\
\hline $\mathrm{SA} 2$ & Span 2 & Middle & - & 46,0425 & - & 39,8004 & - & 35,8942 \\
\hline SA2 & Span 2 & End & $-32,8738$ & - & $-27,6041$ & - & $-1,5423$ & - \\
\hline SA3 & Span 1 & Start & $\begin{array}{c}- \\
135,6903 \\
\end{array}$ & - & $\begin{array}{c}- \\
159,6478 \\
\end{array}$ & - & $-167,0986$ & - \\
\hline SA3 & Span 1 & Middle & - & 68,8953 & - & 56,7069 & - & 50,299 \\
\hline SA3 & Span 1 & End & $\begin{array}{c}- \\
171,6262 \\
\end{array}$ & - & $\begin{array}{c}- \\
199,9588 \\
\end{array}$ & - & $-219,4836$ & - \\
\hline SA3 & Span 2 & Start & $\begin{array}{c}- \\
160,1758 \\
\end{array}$ & - & $\begin{array}{c}- \\
183,2327 \\
\end{array}$ & - & $-197,0077$ & - \\
\hline SA3 & Span 2 & Middle & - & 57,7998 & - & 46,7838 & - & 40,5463 \\
\hline SA3 & Span 2 & End & $\begin{array}{c}- \\
155,6906\end{array}$ & - & $\begin{array}{c}- \\
177,3231\end{array}$ & - & $-189,9411$ & - \\
\hline SA4 & Span 1 & Start & $-2,1322$ & - & 0 & - & 0 & - \\
\hline SA4 & Span 1 & Middle & - & 56,1633 & - & 48,6749 & - & 44,5267 \\
\hline SA4 & Span 1 & End & $-38,5626$ & - & $-33,5171$ & - & $-28,9829$ & - \\
\hline SA4 & Span 2 & Start & $-38,5626$ & - & $-33,5171$ & - & $-28,9829$ & - \\
\hline SA4 & Span 2 & Middle & - & 43,836 & - & 37,6812 & - & 33,9769 \\
\hline SA4 & Span 2 & End & $-33,6508$ & - & $-28,49$ & - & $-24,0651$ & - \\
\hline SA5 & Span 1 & Start & $\begin{array}{c}- \\
131,5288 \\
\end{array}$ & - & $\begin{array}{c}- \\
155,1542 \\
\end{array}$ & - & $-162,5333$ & - \\
\hline SA5 & Span 1 & Middle & - & 67,6819 & - & 56,0159 & - & 49,7282 \\
\hline SA5 & Span 1 & End & $\begin{array}{c}- \\
165,0343 \\
\end{array}$ & - & $\begin{array}{c}- \\
192,3465 \\
\end{array}$ & - & $-211,0243$ & - \\
\hline SA5 & Span 2 & Start & $\begin{array}{c}- \\
153,3877\end{array}$ & - & $\begin{array}{c}- \\
175,1145\end{array}$ & - & $-187,591$ & - \\
\hline SA5 & Span 2 & Middle & - & 56,2336 & - & 45,691 & - & 39,6994 \\
\hline SA5 & Span 2 & End & $\begin{array}{c}- \\
148,7521 \\
\end{array}$ & - & $-169,006$ & - & $-180,2804$ & - \\
\hline
\end{tabular}


Tabel 2. Geser Pons tanpa drop panel Finite Element Analysis (FEA)

\begin{tabular}{ccccl}
\hline Titik & $\begin{array}{c}\text { Tegangan Geser } \\
\text { Pons (Mpa) }\end{array}$ & $\begin{array}{c}\text { Tegangan } \\
\text { Tahanan Geser } \\
(\mathrm{MPa})\end{array}$ & $\begin{array}{c}\text { Rasio Tegangan } \\
\text { Geser Pons/ } \\
\text { Tegangan Tahanan } \\
\text { Geser }\end{array}$ & Status \\
\hline $\mathrm{A}$ & 2,5637 & 1,3644 & 1,879 & Failed \\
\hline $\mathrm{B}$ & 2,4653 & 1,3644 & 1,8069 & Failed \\
\hline $\mathrm{C}$ & 2,3319 & 1,3644 & 1,7091 & Failed \\
\hline $\mathrm{D}$ & 1,7803 & 1,329 & 1,3396 & Failed \\
\hline $\mathrm{E}$ & 1,6196 & 1,329 & 1,2187 & Failed \\
\hline $\mathrm{F}$ & 1,4523 & 1,329 & 1,0928 & Failed
\end{tabular}

Tabel 3. Geser Pons tanpa drop panel Teoritis

\begin{tabular}{ccccl}
\hline Titik & $\begin{array}{c}\text { Tegangan Geser } \\
\text { Pons (Mpa) }\end{array}$ & $\begin{array}{c}\text { Tegangan } \\
\text { Tahanan Geser } \\
(\mathrm{MPa})\end{array}$ & $\begin{array}{c}\text { Rasio Tegangan } \\
\text { Geser Pons/ } \\
\text { Tegangan Tahanan } \\
\text { Geser }\end{array}$ & Status \\
\hline $\mathrm{A}$ & 2,7127 & 1,3555 & 2,001 & Failed \\
\hline $\mathrm{B}$ & 2,60497 & 1,336 & 1,949 & Failed \\
\hline $\mathrm{C}$ & 2,4975 & 1,336 & 1,869 & Failed \\
\hline $\mathrm{D}$ & 1,8031 & 1,2967 & 1,390 & Failed \\
\hline $\mathrm{E}$ & 1,69525 & 1,2967 & 1,307 & Failed \\
\hline $\mathrm{F}$ & 1,58228 & 1,2967 & 1,220 & Failed \\
\hline
\end{tabular}

Tabel 4. Perbedaan Geser Pons tanpa drop panel Teoritis dan Finite Element Analysis (FEA)

\begin{tabular}{cccc}
\hline Titik & $\begin{array}{c}\text { Tegangan Geser } \\
\text { Pons }(\%)\end{array}$ & $\begin{array}{c}\text { Tegangan } \\
\text { Tahanan Geser } \\
(\%)\end{array}$ & $\begin{array}{c}\text { Rasio Tegangan Geser Pons/ Tegangan Tahanan } \\
\text { Geser }(\%)\end{array}$ \\
\hline A & 5,49 & 0,65 & 6,09 \\
\hline B & 5,36 & 2,12 & 7,29 \\
\hline C & 6,63 & 2,12 & 8,55 \\
\hline D & 1,26 & 2,49 & 3,62 \\
\hline E & 4,46 & 2,49 & 6,75 \\
\hline F & 8,21 & 2,49 & 10,4 \\
\hline
\end{tabular}




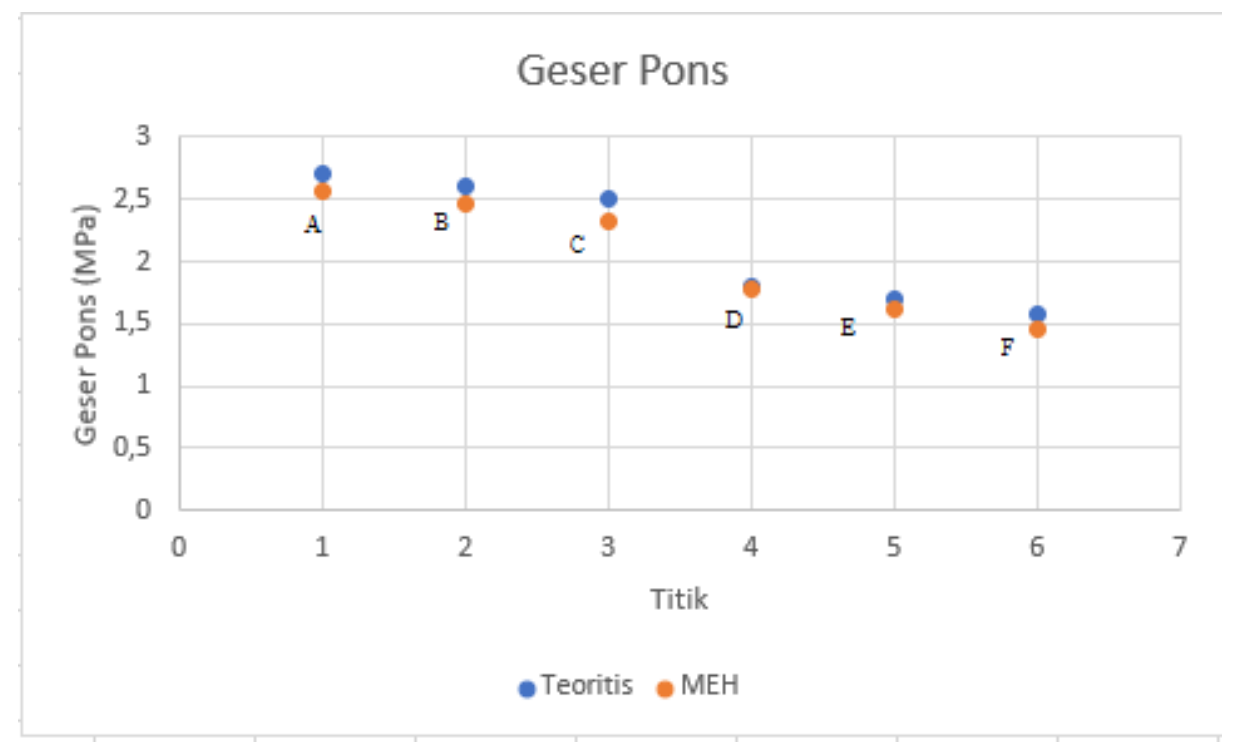

Gambar 5. Grafik perbedaan geser pons analisis MEH dan Teoritis

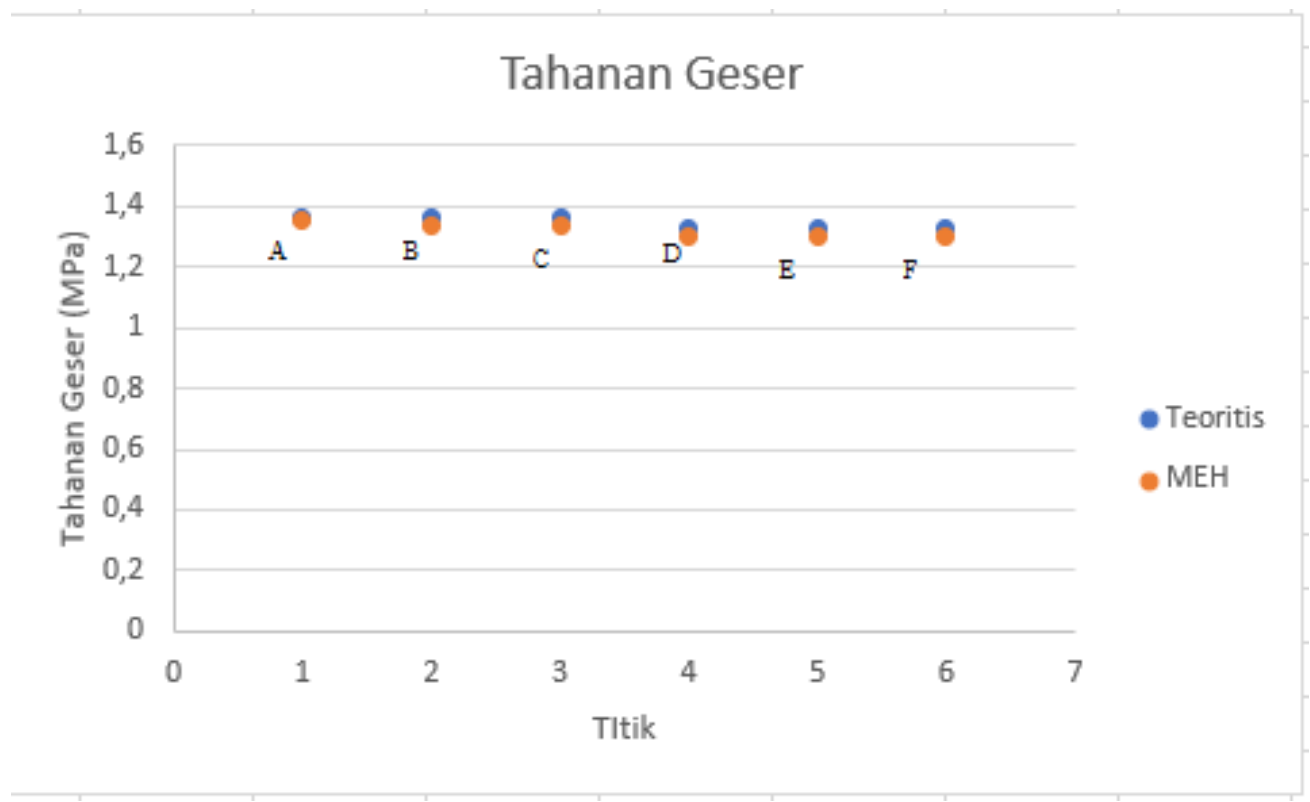

Gambar 6. Grafik perbedaan tahanan geser analisis MEH dan Teoritis

\section{KESIMPULAN DAN SARAN}

\section{Kesimpulan}

Berdasarkan hasil analisis program finite element analysis dan analisis teoritis SNI, didapatkan beberapa kesimpulan sebagai berikut.

1. Drop Panel mereduksi tegangan geser pons pada struktur. Pada kondisi tanpa drop panel, geser pons lebih besar daripada pada kondisi dengan adanya drop panel. Hal ini dibuktikan dengan nilai geser pons yang timbul. Misalnya pada titik A. Tanpa drop panel nilai tegangan geser pons adalah 2,5637 MPa sedangkan dengan drop panel $75 \mathrm{~mm}$ nilai tegangan geser pons turun menjadi 1,6135 $\mathrm{MPa}$.

2. Semakin tebal drop panel, semakin kecil tegangan geser pons yang timbul. Hal ini dapat dilihat pada titik A misalnya. Besarnya tegangan geser pons dengan ketebalan drop panel yang bervariasi dapat dilihat pada: 


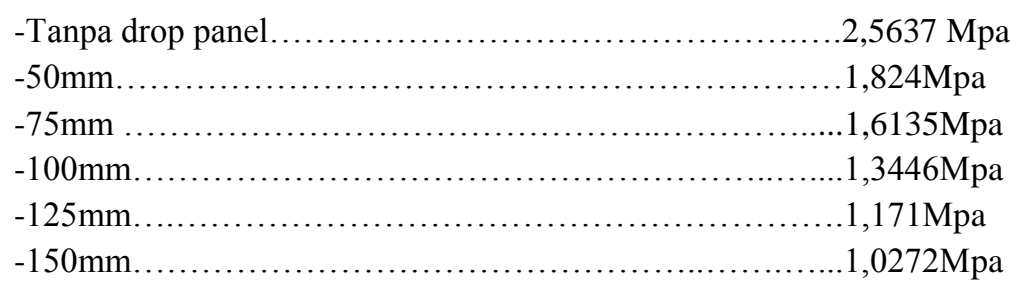

3. Drop Panel memperkecil momen lentur pada daerah lapangan, namun memperbesar momen lentur pada daerah tumpuan.

4. Semakin besar ukuran drop panel, maka tegangan geser pons yang dihasilkan akan semakin kecil. Contohnya drop panel pada daerah tengah dan drop panel pada daerah tepi. Pada daerah tengah tegangan geser pons yang timbul lebih kecil daripada tegangan geser pons yang timbul pada daerah tepi sebab ukuran drop panel pada daerah tengah lebih besar.

5. Analisis Metode Elemen Hingga pada flat slab menghasilkan nilai momen lentur rata-rata berbeda $20 \%$ dari analisis teoritis (berdasarkan SNI), nilai tegangan geser pons rata-rata berbeda 5\%, dan tegangan tahanan geser rata-rata berbeda $2 \%$.

\section{Saran}

Berdasarkan proses pengerjaan studi ini ditemukan beberapa kesulitan, maka dari itu penulis memberikan saran untuk studi selanjutnya :

1. Untuk penelitian selanjutnya dapat dicoba untuk memperhitungkan gaya gempa/gaya lateral.

2. Dapat dicoba untuk menggunakan tinggi kolom yang bervariasi, apakah mempengaruhi nilai momen lentur dan gaya geser pons.Dapat dicoba penelitian pengaruh luas pengaku terhadap kuat tekan profil dengan nilai rasio kelangsingan lainnya.

3. Dapat dicoba dengan ketebalan pelat lantai yang bervariasi, untuk melihat besarnya pengaruh yang ditimbulkan.

\section{DAFTAR PUSTAKA}

Chaudari, Yogesh A. (2016). Finite Element Analysis of Effect of Punching Shear in Flat Slab Using Ansys 16.0. India: ,Sapkal Knlowedge Hub College of Engineering.

Chavan, Gaurav Ravindra. (2016). Analysis and Design of Flat Slab. India: Walchand College of Engineering.

Indonesia, Badan Standarisasi Nasional. (2013) Persyaratan Beton Strutural untuk Bangunan Gedung (SNI $2847-$ 2013). Jakarta: Badan Standarisasi Nasional.

Institute, American Concrete. (2014). Building Code Requirements for Structural Concrete (ACI 318-14). America: American Concrete Institute.

Priya M P and 2Santhi A S. (2018). Experimental Study on the Behavior of Flat Slab Under Different Support Conditions. India: VIT University

Prof G. N. Shete. Analysis and Design of Flat slab with various shapes. (2014). India : M.S Bidve Engineering College, Latur, Maharashtra, India

R.S.More1, V. S. Sawant. (2013). Analysis of Flat Slab R. India: University of Pune.

Ruiz, Miguel Fernandez PhD. (2010). Performance and Design of Punching Shear Reinforcing System. Switzerland : Ecole Polytechnique Federale de Lausanne. 

